\title{
Effect of Engine Speed on In-Cylinder Tumble Flows in a Motored Internal Combustion Engine - An Experimental Investigation Using Particle Image Velocimetry
}

\author{
B. Murali Krishna and J.M. Mallikarjuna* \\ Internal Combustion Engines Laboratory, Department of Mechanical Engineering \\ Indian Institute of Technology Madras, Chennai - 600036, India \\ *Email:jmmallik@iitm.ac.in
}

(Received February 10, 2009; accepted August 8, 2009)

\begin{abstract}
Now-a-days, the stratified and direct injection spark ignition engines are becoming very popular because of their low fuel consumption and exhaust emissions. But, the challenges to them are the formation and control of the charge which is mainly dependent on the in-cylinder fluid flows. Today, an optical tool like particle image velocimetry (PIV) is extensively used for the in-cylinder fluid flow measurements. This paper deals with the experimental investigations of the in-cylinder fluid tumble flows in a motored internal combustion engine with a flat piston at different engine speeds during intake and compression strokes using PIV. The two-dimensional in-cylinder flow measurements and analysis of tumble flows have been carried out in the combustion space on a vertical plane at the cylinder axis. To analyze the fluid flows, ensemble average velocity vectors have been used. To characterize the tumble flow, tumble ratio has been estimated. From the results, it is found that the tumble ratio mainly varies with crank angle positions. At the end of compression stroke, maximum turbulent kinetic energy is more at higher engine speeds. Present study will be very useful in understanding the effect of engine speeds on the in-cylinder fluid tumble flows under real engine conditions.
\end{abstract}

Keywords: In-cylinder motion, Raw images, Velocity field, TKE, Tumble ratio, PIV.

\section{AbBreviations}

$2 \mathrm{D}$

ATKE Average turbulent kinetic energy

BDC Bottom dead center

CAD Crank angle degree

CBCV Cycle by cycle variation

CCD Charge coupled device

$\mathrm{CCW}$ Counter clock wise

CFD Computational fluid dynamics

CW Clockwise

FOV Field of view

GDI Gasoline direct injection

HWA Hot wire anemometer

\section{INTRODUCTION}

In an IC engine, the combustion process and emission formation are mainly dependent on the in-cylinder fluid flows. Therefore, understanding the in-cylinder fluid flows in an IC engine has a very good scope. Previously, to measure the in-cylinder flows, tools like HWA, LDA etc. were used. However, these can measure the in-cylinder fluid flows only at a few locations, but fails to give the full view of the flow structure instantaneously. Now-a-days, an optical tool like PIV is used for the in-cylinder fluid flow

$\begin{array}{ll}\text { IC } & \text { Internal combustion } \\ \text { IVO } & \text { Intake valve opening } \\ \text { LDA } & \text { Laser doppler anemometry } \\ \text { LIF } & \text { Laser induced fluorescence } \\ \text { PIV } & \text { Particle image velocimetry } \\ \text { PTV } & \text { Particle tracking velocimetry } \\ \text { RMS } & \text { Root mean square } \\ \text { SI } & \text { Spark ignition } \\ \text { SIDI } & \text { Spark ignition direct injection } \\ \text { TDC } & \text { Top dead centre } \\ \text { TKE } & \text { Turbulent kinetic energy } \\ \text { TR } & \text { Tumble ratio }\end{array}$

measurements. These are non-intrusive in nature, have high spatial and temporal resolution, and possible to visualize the whole fluid flow field instantaneously.

Previously, Heywood (1988) reported that generating a significant vortex flow (swirl and tumble) inside the IC engine cylinder during the intake process generates high turbulence during the later stages of the compression stroke leading to fast burning rates. Abdullah et al. (2008) made the CFD analysis to study the in-cylinder fluid flows, air-fuel mixing, combustion process and emissions formation with different injection and 
ignition timings in a compressed natural gas direct injection engine. They reported that slightly retarded injection and ignition timings could reduce the $\mathrm{CO}$ and NOx levels with improved performance. Corcione and Valentino (1994) made measurements using LDV at a diametric plane of a diesel engine and found the linear dependence of mean fluid motion and turbulence on the engine speed in the range 1000-3000 rev/min.

Fraidal et al. (1996) and Zhao et al. (1999) reported by their investigations that the GDI is the ultimate strategy for fuel economy improvement. They have suggested the late injection and stratified charge combustion during part-load operation, early injection and homogeneous charge combustion during full-load operation. Hill and Zhang (1994) reported that vortex flows could significantly increase the turbulence during the combustion period, leading to reduced burning time and increased thermal efficiency in the premixed SI engines. Kume et al. (1996), Anderson et al. (1996) and Geiger et al. (1999) observed an improved volumetric efficiency by about $2-3 \%$, use of high compression ratio and improved part-load fuel consumption by about $5 \%$ with GDI engine over conventional port injection engine. Kuwahara and Ando (2000) made the engine incylinder flow studies using PTV and reported that the combustion control could be achieved through a effective turbulence in a premixed lean burn engine and control of air-fuel mixing in a GDI engine.

Valentino et al. (1993), Reeves et al. (1999), Li et al. (2001) and Yasar et al. (2006) conducted PIV measurements on various engines and reported that the flow structure changes substantially along the cylinder length due to the geometry of the intake port and tumble flow during the intake stroke. Stansfield et al. (2006) made the in-cylinder flow measurements using PIV at the end of intake stroke on a plane in between the intake valves of a single cylinder optical engine at the engine speeds of 750, 2000 and $3500 \mathrm{rev} / \mathrm{min}$. They have reported that TR significantly changed for the engine speeds in between 2000 and $3500 \mathrm{rev} / \mathrm{min}$. Nadarajah et al. (1998) and Auriemma et al. (2001) carried out experimental investigations using LDA to study the engine in-cylinder flows and reported that the flow structure during the intake stroke was very much affected by the intake valve lifts and also found a strong flow reversal just below the intake valve at time of intake valve closure. Khalighi (1991) made the incylinder flow measurements using PTV and reported that the swirl and tumble flows should be optimum in order to have good turbulence during combustion. Li et al. (2002) applied the digital PIV technique to study the in-cylinder flows in a single-cylinder engine and estimated the velocity dependent parameters viz. turbulent length scale, vorticity and strain rate distribution, etc.

The above discussion clearly depicts that a good understanding of the in-cylinder fluid flows in an IC engine is very much essential for the optimization of the combustion chamber for better performance in the modern IC engines. The aim of the present study is to measure the in-cylinder fluid tumble flows at a vertical (tumble) plane in a single-cylinder, two-valve, IC engine with a flat piston under motored conditions at the engine speeds of $400,600,800$ and $1000 \mathrm{rev} / \mathrm{min}$., at various CADs during intake and compression strokes using PIV.

\section{EXPERIMENTAL SETUP}

A single-cylinder, vertical, two-valve, air-cooled engine (Table 1) was coupled to an induction motor of $5 \mathrm{hp}$ through an electronic speed controller. The maximum speed of the motor is $1500 \mathrm{rev} / \mathrm{min}$. In this study, the motor along with the engine is run at the speeds of 400 , 600,800 and $1000 \mathrm{rev} / \mathrm{min}$. In order to facilitate the PIV measurements, an extension of the cylinder liner is made using a transparent cylinder ring of plexiglass to a height of $35 \mathrm{~mm}$ above the original liner. By this, it is possible to have a FOV of size 87.5 by $35 \mathrm{~mm}$ for visualization. In order to maintain the required compression ratio $(10: 1)$, the piston crown is raised accordingly. The intake manifold of the engine is connected to a plenum to mix and supply the air along with seeding particles with uniform distribution of them. The schematic and photographic view of the experimental setup is shown in Figs. 1 and 2 respectively. Figure 3 shows the exploded view of the transparent cylinder ring used in this study.

The PIV system consists of a double pulsed ND-YAG laser with $200 \mathrm{~mJ} /$ pulse energy at $532 \mathrm{~nm}$ wave length, a CCD camera of resolution 2048 by 2048 pixels with a frame rate of 14 per second and a set of laser and camera controllers, and a data acquisition system with a software (Fig. 1). The triggering signals for the laser and camera are generated by a crank angle encoder mounted on the engine crankshaft with a resolution of one CAD. These signals are supplied to the laser and camera controllers via a signal modulator. A master signal from the crank angle encoder is set to occur at the suction TDC of the engine (considered as zero $\mathrm{CAD}$ ). The triggering signals at the required $\mathrm{CAD}$ can be set within the software. A seeding unit is used to generate the fine particles of one micron size with $\mathrm{Di}$ Ethyl-Hexyl-Sebacat $\left(\mathrm{C}_{26} \mathrm{H}_{50} \mathrm{O}_{4}\right)$ as a seeding material. The seeding particle density is controlled accurately by varying the amount of pressurized air supplied to the seeding unit. The laser sheet of $0.5 \mathrm{~mm}$ thickness is aligned with and camera view is set to FOV on a vertical plane passing through the axis of the cylinder.

In this study, in-cylinder flow measurements have been done during intake (30 to $180 \mathrm{CADs}$ ) and compression (210 to 330 CADs) strokes in a step of 30 CAD. At every measuring point, 500 image pairs are recorded and stored. The time interval $(\Delta \mathrm{t})$ between successive images is set based on the pixel shift (5 pixels), FOV, maximum expected velocity of fluid in FOV and the resolution of the camera (DAVIS, 2006; Murali Krishna et al. 2008). The ' $\Delta \mathrm{t}$ ' used in this study at different engine speeds are shown in the Table 2. To minimize the light reflections, a band-pass filter with central wavelength of $532 \mathrm{~nm}$ is mounted on the CCD camera. During PIV recording, camera focus is set to $3(\mathrm{f}=3$ ) to obtain sharp particle images. DAVIS (Data acquisition and visualization software) is used for image acquisition and data post-processing. During postprocessing, interrogation window size of 32 by 32 pixels with multi-pass cross-correlation algorithm has 
been used (Raffel, 1998). The ensemble average velocity fields are computed from 500 raw image pairs, and also TR and maximum turbulent kinetic energy (TKE) are calculated at every measured CAD.

\section{RESULTS AND DISCUSSION}

In general, in-cylinder flows in an IC engine are of two types viz. flow parallel (swirl) and perpendicular (tumble) to the cylinder axis. These flows are generated in the combustion chamber during the intake stroke due to piston shape, intake manifold orientation, intake valve lift and engine speed, etc. For most of the modern stratified charge and direct injection SI engines, tumble flows are more crucial than the swirl flows for the proper mixing of air and fuel, and for high flame propagation rate. Also a well defined (single vortex) swirl or tumbling flow structure is more stable than other large scale in-cylinder flows and they may break up later in the cycle giving higher turbulence during combustion (Khalighi, 1991). Therefore, this study is focused on the in-cylinder tumble flows. Figures 4-11 show the ensemble average velocity vectors of the incylinder tumble flows with superimposed streamline patterns under various engine conditions. In all these figures, constant length of velocity vector is used with different colours to represent their magnitude. Each of these figures has their own colour scale to represent the velocity magnitudes. However, for more clarity, the average and maximum values of the velocity vectors at different conditions are given in Table 3 .

\subsection{Flow Patterns during Intake Stroke}

Figures 4 to 7 show the ensemble average velocity vector fields with superimposed streamline patterns during intake stroke from 30 to 180 CADs with an interval of $30 \mathrm{CAD}$ for various engine speeds. Figure $4 \mathrm{a}$ shows the ensemble average velocity vectors for 30 CAD during intake stroke at an engine speed of 400 $\mathrm{rev} / \mathrm{min}$. At this CAD, opening of the intake valve is very less (about 15\%). Also, at the left side of the intake valve, there is a very narrow passage for the air to enter into the cylinder causing minimum air entry at that side. Therefore, more amount of air flows towards right side. The air enters the cylinder at the right side in the form of a jet almost parallel to the cylinder head. Air jet reaches the right side cylinder wall, strikes it and diverted downwards. Again it strikes the piston top surface forming a $\mathrm{CW}$ vortex. In the similar manner, small amount of air entering the cylinder space at the left side of the intake valve, strikes the left side cylinder wall and diverted downwards and again strikes the piston top surface diverting upwards forming a $\mathrm{CCW}$ vortex. Since the air flow at the top of the combustion chamber is more predominant, obviously central cylinder space has become a low pressure zone. Therefore, some amount of air from the right and left side of the cylinder space is trying to rush towards the low pressure zone and mixing with the ambient air rapidly. This may also lead to form turbulence. These phenomena are clearly depicted in Fig.4a. At the engine speeds of 600 and $800 \mathrm{rev} / \mathrm{min}$., the overall in-cylinder flow pattern is almost similar to that of $400 \mathrm{rev} / \mathrm{min}$. However, at the right side cylinder space, the flow pattern looks like somewhat disturbed as shown in Figs. 5a and $6 \mathrm{a}$. This may be due to the higher turbulent intensity at higher engine speeds. From Fig. 7a, at an engine speed of $1000 \mathrm{rev} / \mathrm{min}$., it is observed that, the vortices which formed at lower engine speeds have been vanished indicating increase in turbulence and rapid mixing of air streams at low pressure zones.

At $60 \mathrm{CAD}$ (Fig. 4b, at $400 \mathrm{rev} / \mathrm{min}$.), the inlet valve has opened by about $60 \%$. Air flow at right side of the inlet valve is no longer parallel to the cylinder head, but it is slightly bent downwards and moving rightwards in the form of a jet. Due to the downward bending of the air jet, some amount of air is forcing to the cylinder space at the right top corner of FOV; however, major part of the air is moving rightwards. Due to comparatively large opening of the inlet valve, air flow rate has been increased and also due to more cylinder space above the piston top, a large $\mathrm{CW}$ vortex has been formed at the right side cylinder space because of the similar phenomena as explained above. Because of the flow diversification at the right region of the cylinder, there exists a flow bifurcation zone as it can be seen as a thick stream line in Fig. 4b. At the left side, in the similar way, a large CCW vortex has been formed. At the center space just below the intake valve, due to the collision of the $\mathrm{CW}$ and $\mathrm{CCW}$ vortices, another bifurcation region has been created. When the engine operates at the speed of 600,800 and $1000 \mathrm{rev} / \mathrm{min}$., even though the overall flow pattern is almost same as explained above, but there are variations in the magnitudes of velocity vectors as shown in Figs. $4 \mathrm{~b}, 5 \mathrm{~b}$ and $6 \mathrm{~b}$. These variations may be due to increased air flow rates at higher engine speeds causing rapid mixing leading to more turbulence.

At 90 CAD (Fig. 4c, $400 \mathrm{rev} / \mathrm{min}$ ), the intake valve has opened about $90 \%$ (full opening at $110 \mathrm{CAD}$ ) and also the piston speed reaches almost its peak at this point and therefore, the air flow rate is maximum at this condition. At this CAD, the air jet at the right side of the intake valve is moving with full speed almost parallel to the cylinder axis. A part of the air flows towards left side, strikes the piston top surface and diverting upwards left forming a large $\mathrm{CW}$ vortex. Other part of the air flows to the right side, after striking the piston top surface is moving further right and striking the right cylinder wall moving upwards right forming a large CCW vortex. The formation of the two large vortices is also assisted by the low pressure regions just below the intake valve and at the right side cylinder space. From Fig. 4c, it is very much clear that at the right side cylinder space below the intake valve, due to the flow diversification, a clearly visible bifurcation zone has been created. The air flow at the left side of the intake valve, after striking the left cylinder wall is entering the left side cylinder space below the intake valve. However, due to the dominant right side air flow, an almost vertical bifurcation zone has been created very close to the left cylinder wall. Almost similar type of flow patterns exist at 90 CAD at the engine speeds of 600,800 and $1000 \mathrm{rev} / \mathrm{min}$., as shown in Figs. $4 c, 5 c$ and $6 \mathrm{c}$ respectively. However, it seems that the size of the $\mathrm{CW}$ vortex below the intake valve is increasing with increase in engine speeds. In addition, at higher engine speeds, flow is more random in nature. 
At 120 CAD (almost full intake valve lift, Fig. 4d, 400 $\mathrm{rev} / \mathrm{min}$ ), the flow pattern is almost similar in nature to that of $90 \mathrm{CAD}$. However, at this CAD, size of the vortices has been increased and it may be due to expansion of the fluid because of the downward movement of the piston. At $150 \mathrm{CAD}$ (Fig. 4e) also, the flow pattern is similar to that of $120 \mathrm{CAD}$; however, the size of two vortices to the right side of the intake valve is shrinking. This may be due to reduction of the air flow rate by the closure of the intake valve and further expansion of the air at this CAD. In addition, a dominant $\mathrm{CCW}$ vortex at left side cylinder space just below the intake valve has been created. At the above CADs, there are no much variations in the flow pattern with the increase in engine speeds (at 600, 800 and $1000 \mathrm{rev} / \mathrm{min}$ ). But, randomness in flow pattern is observed as shown in Figs. $4 \mathrm{~d}, 5 \mathrm{~d}$ and $6 \mathrm{~d}$, and $4 \mathrm{e}, 5 \mathrm{e}$ and $6 \mathrm{e}$.

At $180 \mathrm{CAD}$ (Fig. 4f, $400 \mathrm{rev} / \mathrm{min}$ ), intake valve opening is very less, hence fresh air entry is also very less. However, the air which was already present during the early part of the cycle is undergoing the changes in flow pattern. From Fig. 4f, it can be observed that, a large $\mathrm{CW}$ vortex has been formed almost dominating the entire cylinder space with center of the vortex almost below the intake valve compared to the flow patterns during other previous CADs. Also, From Fig. 4f, it can be observed that the formation of a small vortex near the top left corner of the FOV. This may be due to the low pressure region at that point because of a large vortex formation at the central cylinder space. From Figs. 4f to 6f, it can also be observed that, at the engine speeds of 600,800 and $1000 \mathrm{rev} / \mathrm{min}$., incylinder flow pattern is dominating by a single large $\mathrm{CW}$ vortex followed by a small vortex at the top left corner. It clearly indicates that the in-cylinder flow pattern has not been affected much by the change in engine speed at the end of intake stroke (at 180 CAD).

\subsection{Flow Patterns during Compression Stroke}

Figures 7 to 10 show the in-cylinder flow pattern during the compression stroke on a central plane from 210 to 330 CADs at the engine speeds of $400,600,800$ and $1000 \mathrm{rev} / \mathrm{min}$. At $210 \mathrm{CAD}$ (Fig. 8a, $400 \mathrm{rev} / \mathrm{min}$ ), a large single $\mathrm{CW}$ vortex created at the end of suction stroke has been shifted towards left side of the cylinder with reduced size. In addition, air flow from the other zones of the cylinder space after striking the right cylinder wall, is trying to form a CCW vortex near the right cylinder wall. Both the vortices are striking each other and forming a bifurcation zone near the right side cylinder space. This may be also due to the upward motion of the piston during compression stroke which is compressing the in-cylinder flow pattern as a whole. From Figs. 8a, 9a and 10a, it can be observed that, at 210 CAD, size of the large single vortex is increasing with almost similar flow pattern as that of $400 \mathrm{rev} / \mathrm{min}$.

At 240 CAD (Fig. 8b, 400 rev/min), there are no much changes in the flow pattern in comparison to $210 \mathrm{CAD}$ except the increase in the size of the single large vortex formed earlier. Also, the bifurcation zone created earlier is trying to move leftwards. When the engine speed is increased, not much variations are taking place in the flow pattern except the increase in randomness of the flow pattern at higher engine speeds as shown in Figs. 9b, 10b and 11b.

At $270 \mathrm{CAD}$ (Fig. 8c, $400 \mathrm{rev} / \mathrm{min}$ ), the flow pattern has been divided almost into three clear zones. At the cylinder space near the right and left cylinder walls, two $\mathrm{CCW}$ vortices are formed and at the center space, a CW vortex has been formed as shown in Fig. 8c. This may be due to the striking of the vertically upward air flow with the cylinder head caused by the upward movement of the piston and also due to the reduction in cylinder space. Additionally, it may be due to the air flow rushing into the low pressure zones at the center cylinder space from the other zones. From Fig. 8c, it can also be observed that two bifurcation zones are created almost at the center space by the interaction of the three vortices dividing the flow field into three zones. Above flow pattern is observed with all the cases of engine speeds with more randomness at higher engine speeds as shown in Figs. 9c, 10c and 11c.

At $300 \mathrm{CAD}$ (Fig. 8d, $400 \mathrm{rev} / \mathrm{min}$ ), the piston has moved further up and thereby reducing the cylinder space further. By this, the large vortices formed earlier have been vanished. From Fig. 8d, it is seen that the entire air flows upward almost maintaining the two bifurcation zones created earlier. In addition, a small vortex has been created at the top left cylinder space in the case of 400 and $600 \mathrm{rev} / \mathrm{min}$ of engine speeds. It may be due to the low pressure zone at those points. However, in the case of 800 and $1000 \mathrm{rev} / \mathrm{min}$ of engine speeds, small vortices have been created at the right side cylinder space. It may due to higher velocities of the $\mathrm{CW}$ vortex at higher engine speeds causing it to move rightwards.

Figure 8e shows the flow pattern at $330 \mathrm{CAD}$ for the engine speed of $400 \mathrm{rev} / \mathrm{min}$. From Fig. 8e, it is observed that there is a clear $\mathrm{CW}$ vortex formation almost at the top center of the combustion space. Normally, in the stratified charge and direct injection SI engines, the spark plug is located almost at the center of the combustion chamber. Therefore, once ignition starts, the air movement and the vortex formation inside the combustion space will aid proper flame propagation leading to effective combustion. The formation of the vortex and $\mathrm{CW}$ air movement are almost evident in all the cases of engine speeds as shown in Figs. 8e to 11e. Therefore, it is very much clear that irrespective of the formation of vortex and air flow pattern at earlier stages of the cycle, a favorable air flow pattern occurs at 330 CAD which is very much useful especially in the case of stratified charge and direct injection SI engines. The air movement at this crank angle position plays a very vital role in proper ignition and higher flame propagation (Khalighi, 1991).

\subsection{Variation of Tumble Ratio}

Unlike swirl ratio which usually obtained through steady flow experiments, the tumble ratio must be evaluated under transient conditions due to the significant effect of the piston and its motion on the incylinder tumble flows (Khalighi, 1991). Also, good fuel stratification could be achieved with strong in-cylinder 
tumble flows ( $\mathrm{Li}, 2005)$. In this study, in-cylinder tumble flow has been characterized by TR as calculated from Eq. (1) which is proposed by Huang et al. (2005). Here, the TR is defined as the ratio of the mean angular velocity of the vortices on the target plane to the average angular velocity of the crank. The negative or positive magnitudes of TR indicate the direction of the overall in-cylinder tumble flow in a given plane as $\mathrm{CW}$ or CCW respectively.

$$
T R=\frac{\sum_{i=1}^{n}\left(\frac{\partial v}{\partial x}-\frac{\partial u}{\partial y}\right) i}{2 n \omega}
$$

Where, numerator is the sum of the vortices, $i$ is the number of grid points setup, $\mathrm{n}$ is the total number of grid points, $\omega$ is the crank shaft angular speed $(\mathrm{rad} / \mathrm{s})$.

As discussed earlier, air entry into the cylinder through the narrow passages of intake valves and cylinder, movement of the piston, interaction of air with cylinder walls and piston surfaces lead to the formation of vortices and orderly movement of air inside the cylinder. Generally, at all the engine speeds, it is observed that the air movement is predominant at the right side cylinder space than at left side. Due to this, for major part of the cycle, air movement is from right to the left side of cylinder space, guided by the piston top surface and cylinder walls leading $\mathrm{CW}$ vortex in most of the measured CADs. This type of in-cylinder flow pattern was also observed by Khalighi (1991) in his study.

The overall in-cylinder air movement is difficult to quantify just by a visual inspection of the velocity vector fields. However, it can be done with the help of TR. Figure 12 shows the variation of the TR with CADs at various engine speeds considered in this study during intake and compression strokes. From Fig. 12, it is observed that the TR ratio is changing its magnitudes (positive to negative or vice versa) indicating the overall air movement changing its direction during the cycle. However, for most part of the intake and compression strokes, general air movement is $\mathrm{CW}$ (negative TR) as shown in Fig. 12. The overall air movement at the end of compression stroke gives a better idea for the engine designers to fix the position of the spark plug and fuel injector (for direct injection engines only) (Hill and Zhang, 1994). Even though, in the present study, only the air flow pattern is considered which is unlikely to happen in the practical SI engines, but it almost depicts the charge flow pattern as well. With increase in engine speed, the TR increases marginally at all the CADs. On the whole, from Fig. 12, it can be observed that the overall flow pattern in the cylinder space is changing to $\mathrm{CW}$ or $\mathrm{CCW}$ directions with CADs. The reasons for this could be: (i) change in the overall flow pattern due to low pressure and bifurcation zones, (ii) change in piston speed with CADs, and (iii) change in the direction of the piston movement during intake and compression strokes. Figure 13 shows the variation of the TR at $330 \mathrm{CAD}$ (almost the end of compression) for all the engine speeds considered. At this CAD, with increase in engine speed, TR magnitude is increasing indicating the increase in overall air movement.

\subsection{Variation of Turbulent Kinetic Energy}

During compression stroke, tumble flow is found to be more effective than swirl for efficient extraction of inertia of the piston movement and also for transferring kinetic energy of the mean motion of the fluid into turbulence later. Also higher turbulence is believed to generate higher flame speed and high reactive flame surface area (Khalighi, 1991). The turbulent kinetic energy of the flow indicates its strength as a whole. Figure 14 shows the variation of the average and maximum TKE with CADs during intake and compression strokes.

The turbulence controls the rate of flow dissipation, heat transfer and the rate of flame propagation and it is quantified by TKE within the cylinder. Here, TKE is calculated using following equations from RMS velocity fields (Reuss et al. 1995).

$$
T K E=\frac{1}{2} \rho V_{r m s}^{2}=\frac{1}{2}\left(\rho u_{r m s}^{2}+\rho v_{r m s}^{2}\right)
$$

Where, $\mathrm{u}$ and $\mathrm{v}$ are the RMS velocity components in the $\mathrm{x}$ and $\mathrm{y}$ directions respectively. Density, $\rho$ is assumed as $1 \mathrm{~kg} / \mathrm{m}^{3}$ for air.

From Fig. 14, it can be observed that both average and maximum TKEs are more for higher engine speeds indicating higher strength of the fluid flows. From Fig. 13, it is also observed that both average and maximum TKE are reaching their peaks at $90 \mathrm{CAD}$. This may be expected because of higher inlet air velocity at this CAD. Variation of TKE with CADs is almost in line with the variation of the average and maximum air velocities at the respective CADs. It means that almost it follows the variation of the inlet average air velocity at a given engine speed. Further, similar type of variation in TKE was reported by $\mathrm{Li}$ (2005). At compression TDC, pure tumble flow generates the better fuel concentration in the vicinity of the spark plug (Alger et al., 2000). Figures 15 and 16 show the plot of average and maximum TKE at 330 $\mathrm{CAD}$ at different engine speeds. It is very much evident from these figures that both the average and maximum TKE are higher at higher engine speeds among the range of speeds considered in this study indicating the advantage of operating the SI engines at higher engine speeds.

\section{CONCLUSIONS}

In this study, from the experimental investigations carried out on the in-cylinder tumble flows using PIV on a single-cylinder, two-valve engine under motoring conditions, the following conclusions are drawn:

- The overall in-cylinder tumble flows are mainly dependent on the crank angle position irrespective of the engine speed.

- For flat top piston, for most part of the intake and compression strokes, the direction of the overall in-cylinder tumble flow is in clockwise direction.

- In-cylinder tumble flow is more dominant at the right half of the cylinder space below the exhaust valve. 
- The tumble ratio varies mainly with crank angle positions and not much affected by the engine speed.

- At the engines speeds considered in this study (400-1000 rev/min), average and maximum TKEs are reaching their peaks at about full intake valve opening position.

- At the end of compression stroke, where spark is suppose to be supplied, both average and maximum TKEs are higher at higher engine speeds among the range of engine speeds considered in this study.

- On the whole, it is found that for an engine equipped with flat piston, TKEs are higher at higher engine speeds among the range of speeds considered in this study.

This study will be useful in understanding the effect of engine speed on the nature of the in-cylinder fluid tumble flow pattern under real engine conditions.

\section{REFERENCES}

Abdullah, S., W.H. Kurniawan and A. Shamsudeen (2008). Numerical Analysis of the Combustion Process in a Compressed Natural Gas Direct Injection Engine. Journal of Applied Fluid Mechanics 1(2), 65-86.

Alger, T., M. Hall and R.D. Matthews (2000). Effects of Swirl and Tumble on In-Cylinder Fuel Distribution in a Central Injected DISI Engine. SAE Paper No. 2000-01-0533.

Anderson, W., J. Yang, D.D. Brehob, J.K. Vallance and R.M. Whiteaker (1996). Understanding the Thermodynamics of Direct Injection Spark Ignition (DISI) Combustion Systems - An Analytical and Experimental Investigation. SAE Paper No. 962018.

Auriemma, M., F.E. Corcione, U.Di Martino and G. Valentino (2001). Analysis of the intake flow in a diesel engine head using dynamic steady flow conditions. SAE Paper No. 2001-01-1307.

DAVIS 7.2 Software Manuals. LaVision, Germany, 2006.

Felice, E., Corcione and G. Valentino (1994). Analysis of In-Cylinder Turbulent Air Motion Dependence on Engine Speed. SAE Paper No. 940284.

Fraidl, G.K., W.F. Piock and M. Wirth (1996). Gasoline Direct Injection: Actual Trends and Future Strategies for Injection and Combustion Systems. SAE Paper No. 960465.

Gerardo, V., D. Kaufman and P. Farrell (1993). Intake Valve Flow Measurements Using PIV. SAE Paper No. 932700.
Heywood, J.B. (1988). Internal Combustion Engine Fundamentals. Pub: McGraw Hill International Editions.

Hill, P.G. and D. Zhang (1994). The effects of swirl and tumble on combustion in spark-ignition engines. International Journal of Progress in Energy and Combustion Science 20, 373-429.

Huang, R.F., C.W. Huang, S.B. Chang, H.S. Yang, T.W. Lin and W.Y. Hsu (2005). Topological flow evolutions in cylinder of a motored engine during intake and compression stroke. Journal of Fluids and Structures 20, 105-127.

Jose, Ge., M. Grigo, O. Lang, P. Wolters and P. Hupperich (1999). Direct Injection Gasoline Engines - Combustion and Design. SAE Paper No. 1999-01-0170.

Khalighi, B. (1991). Study of the intake tumble motion by flow visualization and particle tracking velocimetry. Journal of Experiments in Fluids 10, 230236.

Kume, T., Y. Lwamoto, K. Lida, M. Murakami, K. Akishino and H. Ando (1996). Combustion Control Technologies for Direct Injection SI Engine. SAE Paper No. 960600.

Kazunari, K. and H. Ando (2000). Diagnostics of incylinder flow, mixing and combustion in gasoline engines. Journal of Measurements Science and Technology 11, R95-R111.

Li, Y., H. Zhao, Z. Peng and N. Ladommatos (2001). Particle image Velocimetry measurement of incylinder flow in internal combustion engines experiment and flow structure analysis. Proc Institution. Mech. Engrs. 216, Part D.

Li, Y., H. Zhao and T. Ma (2006). Flow and Mixture Optimization for a Fuel Stratification Engine Using PIV and PLIF Techniques. Journal of Physics: Conference Series 45, 59-68.

Murali Krishna, B., and J.M. Mallikarjuna (March, 2008). Intake valve flow analysis in a direct injection diesel engine using particle image velocimetry. Proceedings of the 2nd International Conference on Recent Advances in Experimental Fluid Mechanics (RAEFM-2008), Vizayawada, India.

Murali Krishna, B., and J.M. Mallikarjuna (March, 2008). Optical Diagnosis of Flow through the Intake Valve in a Direct Injection Diesel Engine. Proceedings of the 15Th ISME International Conference on New Horizons of Mechanical Engineering (ISME-2008), Bhopal, India.

Nadarajah, S., S. Balabani, M.J. Tindal and M. Yianneskis (2007). The effect of swirl on the annular flow past an axi-symmetric poppet valve. Proceedings of Institution of Mech. Engrs. 212, Part C. 
Stansfield, P., G. Wigley, T. Justham, J. Catto and G. Pitcher (2006). PIV analysis of in-cylinder flow structures over a range of realistic engine speeds. Journal of Experiments in Fluids 43, 135-146.

Raffel, M., C. Willet and J. Kompenhans (1998). Particle Image Velocimetry-A Practical Guide. Pub: Springer-Verlag Berlin Heidelberg, Germany.

Reuss, D.L., T.W. Kuo, B. Khalighi, D. Haworth and M. Rosalik (1995). Particle Image Velocimetry Measurements in a High-Swirl Engine used for Evaluation of Computational Fluid Dynamics Calculations. SAE Paper No 952381.
Reeves, M., M.J. Haste and N.A. Halliwell (1999). Barrel swirl breakdown in spark-ignition engines: insights from particle image Velocimetry measurements. Proceedings of IMechE 213, Part D.

Yasar, A., B. Sahin, H. Akilli and K. Aydin (2006). Effect of inlet port on the flow in the cylinder of an internal combustion engine. Proceedings of Institution of Mech. Engrs. 220, Part C: J. Mechanical Engineering Science.

Zhao, F., M.C. Lai, D.L. Harrington (1999). Automotive spark-ignited direct-injection gasoline engines. International Journal of Progress in Energy and Combustion Science, Paper No. 25, 437-562.

Table 1 Engine specifications

\begin{tabular}{|l|c|}
\hline Bore $\mathrm{x}$ stroke (mm) & $87.5 \times 110$ \\
\hline Compression ratio & $10: 1$ \\
\hline Rated engine speed (rev/min) & 1500 \\
\hline Maximum valve lift (mm) & 7.6 \\
\hline Intake/exhaust port diameter (mm) & 28.5 \\
\hline Intake valve opening (CAD bTDC) & 4.5 \\
\hline Intake valve closing (CAD aBDC) & 35 \\
\hline Exhaust valve opening (CAD bBDC) & 35 \\
\hline Exhaust valve closing (CAD aTDC) & 4.5 \\
\hline
\end{tabular}

Table 2 Time interval between images

\begin{tabular}{|c|c|c|c|c|}
\hline \multicolumn{5}{|c|}{ Time interval, $\Delta \mathrm{t}(\mu \mathrm{s})$} \\
\hline \multirow{2}{*}{ Processes } & \multicolumn{4}{|c|}{ Engine speeds (rev/min) } \\
\cline { 2 - 5 } & 400 & 600 & 800 & 1000 \\
\hline Intake & 13 & 10 & 8 & 6 \\
\hline Compression & 18 & 12 & 10 & 8 \\
\hline
\end{tabular}

Table 3 Magnitudes of the velocity vectors at various conditions

\begin{tabular}{|c|c|c|c|c||c|c|c|c|}
\hline \multirow{3}{*}{ CAD } & \multicolumn{7}{|c||}{ Average velocity, (m/s) } & \multicolumn{5}{c|}{ Maximum velocity, (m/s) } \\
\cline { 2 - 9 } & \multicolumn{9}{|c|}{ Engine speed (rev/min) } \\
\cline { 2 - 9 } & 400 & 600 & 800 & 1000 & 400 & 600 & 800 & 1000 \\
\hline 30 & 2.4 & 2.7 & 2.9 & 3.4 & 8.2 & 9.4 & 11.8 & 9.9 \\
\hline 60 & 2.6 & 2.7 & 3.1 & 8.3 & 9.8 & 11.9 & 12.6 & 23.4 \\
\hline 90 & 2.4 & 3.2 & 3.9 & 4.9 & 10.9 & 13.3 & 12.4 & 25.4 \\
\hline 120 & 2.4 & 2.5 & 3.5 & 4.8 & 10.9 & 10.6 & 12.5 & 22.0 \\
\hline 150 & 1.9 & 2.0 & 2.2 & 4.4 & 7.8 & 11.6 & 12.2 & 19.9 \\
\hline 180 & 1.3 & 1.5 & 2.0 & 3.0 & 3.7 & 5.5 & 6.8 & 10.7 \\
\hline 210 & 0.8 & 1.4 & 2.1 & 2.6 & 2.6 & 3.8 & 6.4 & 7.0 \\
\hline 240 & 0.9 & 1.0 & 1.2 & 2.9 & 2.4 & 3.1 & 4.3 & 7.3 \\
\hline 270 & 0.7 & 1.2 & 1.8 & 2.8 & 2.6 & 4.0 & 6.3 & 9.3 \\
\hline 300 & 1.4 & 1.6 & 2.0 & 2.9 & 3.7 & 4.5 & 5.7 & 9.0 \\
\hline 330 & 1.0 & 1.4 & 1.7 & 3.0 & 2.1 & 3.0 & 3.7 & 7.1 \\
\hline
\end{tabular}




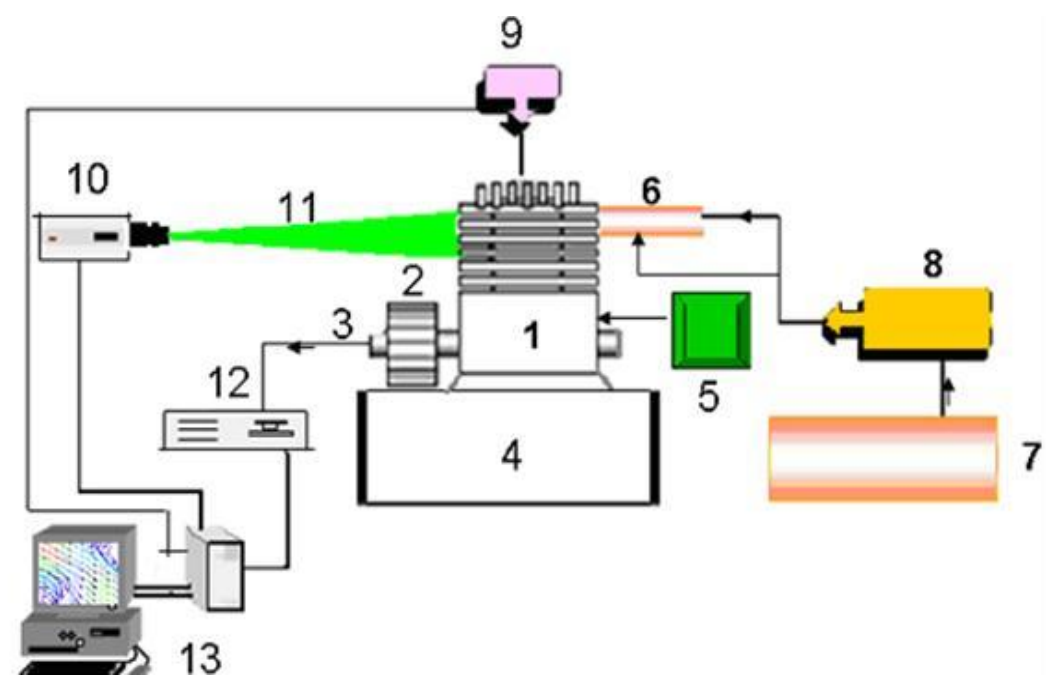

1. Engine, 2. Motor, 3. Crank angle encoder, 4. Test bench, 5. Speed controller, 6. Intake plenum, 7. Air compressor, 8. Seeder, 9. Camera, 10. ND-YAG Laser, 11. Laser sheet, 12. Signal modulator, 13. Data acquisition system

Fig. 1. Schematic diagram of the experimental setup

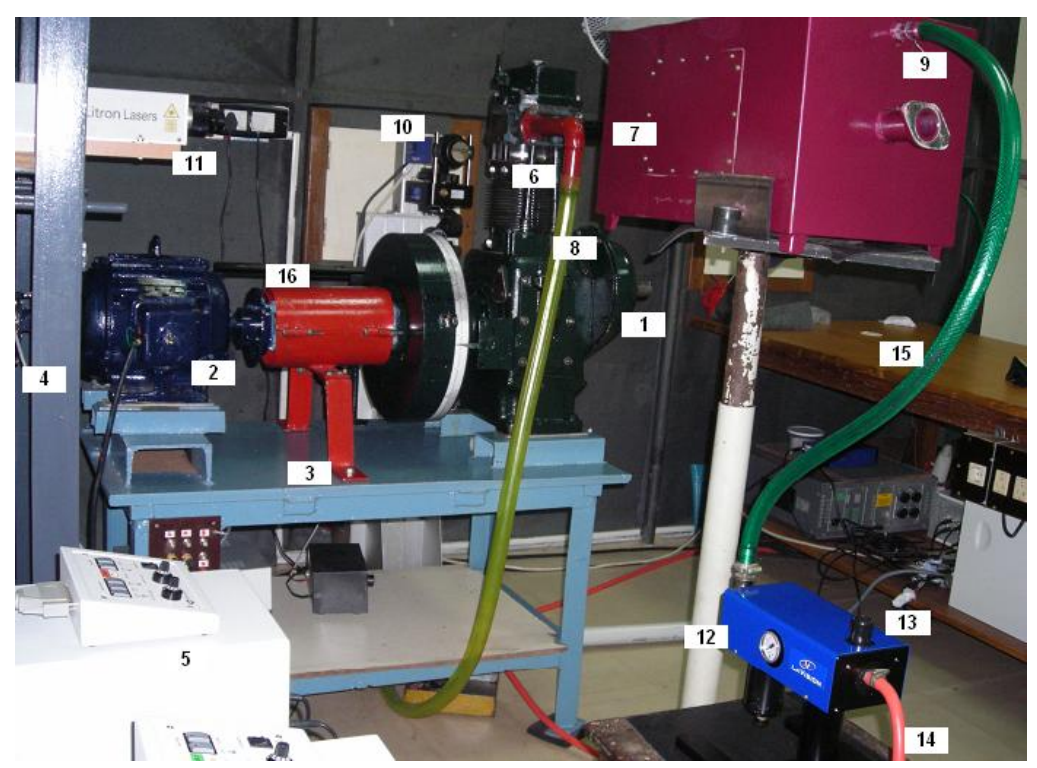

1. Engine, 2. Motor, 3. Test bench, 4. Encoder, 5. Laser controller, 6. Transparent cylinder, 7. Intake plenum, 8. Exhaust, 9. Air intake, 10. CCD Camera, 11. Laser, 12. Seeder, 13. Regulator, 14. Compressor connection, 15. Seeding supply, 16. Coupling

Fig. 2. Photographic view of the experimental setup

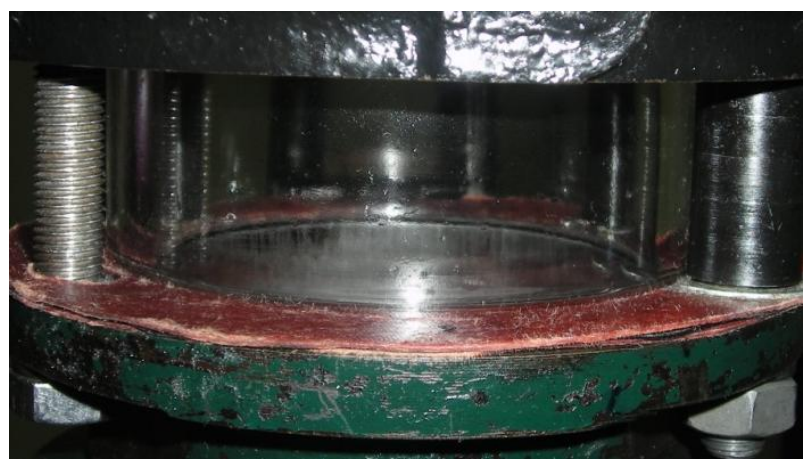

Fig. 3. Detailed view of the transparent cylinder liner for optical access 


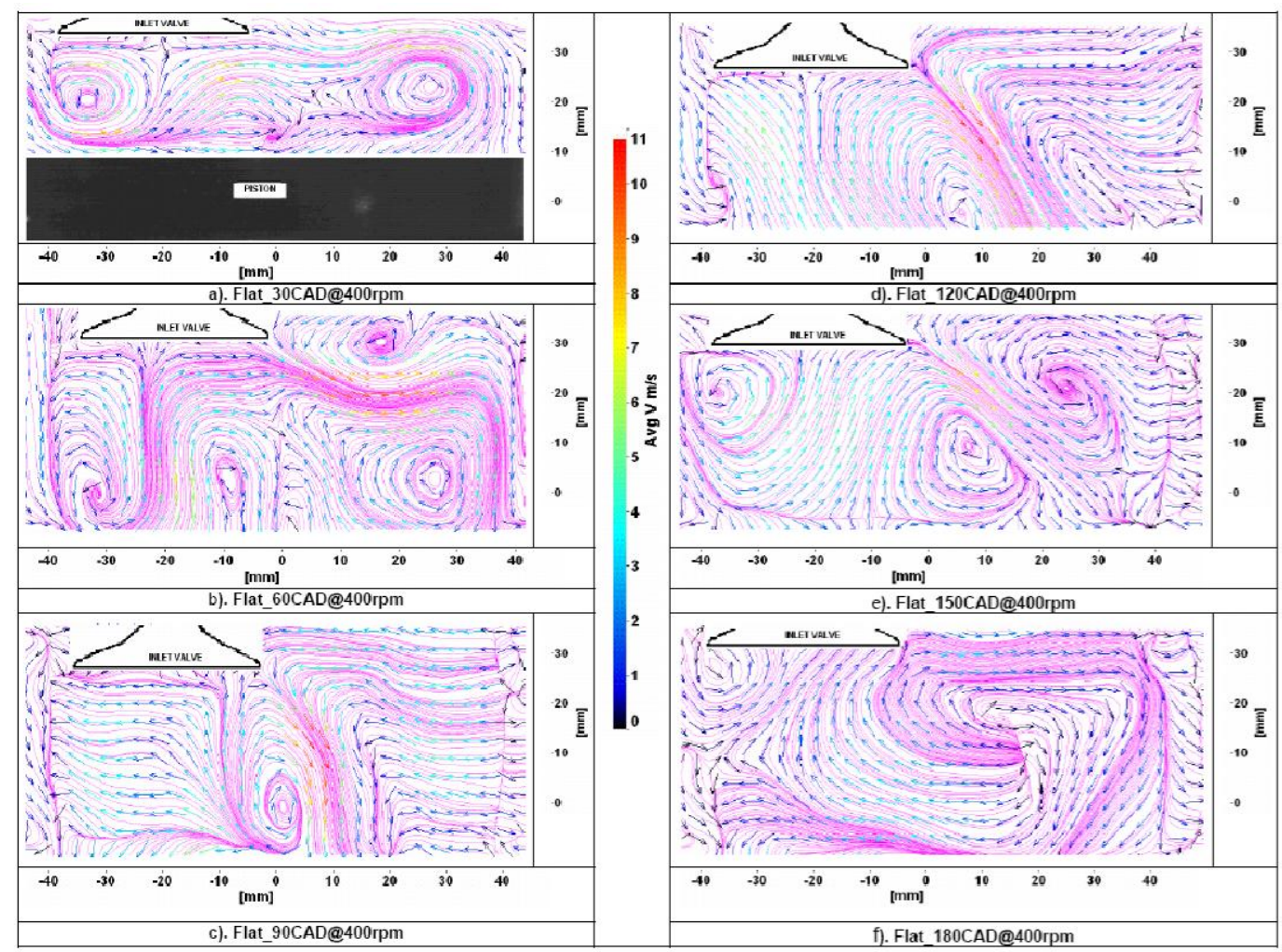

Fig. 4. The ensemble average velocity vectors during intake stroke at an engine sped of $400 \mathrm{rev} / \mathrm{min}$.

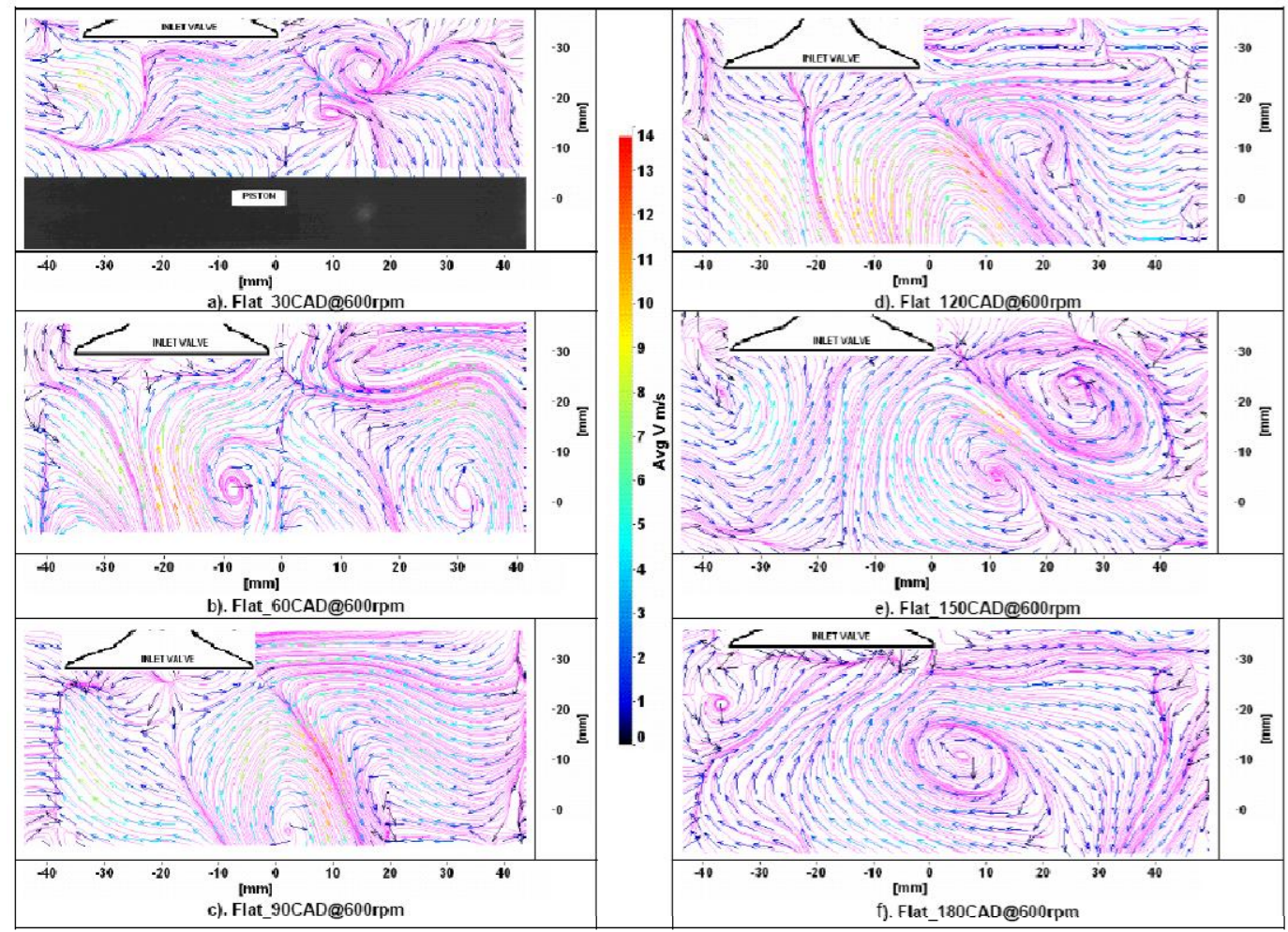

Fig. 5. The ensemble average velocity vectors during intake stroke at an engine speed of $600 \mathrm{rev} / \mathrm{min}$. 


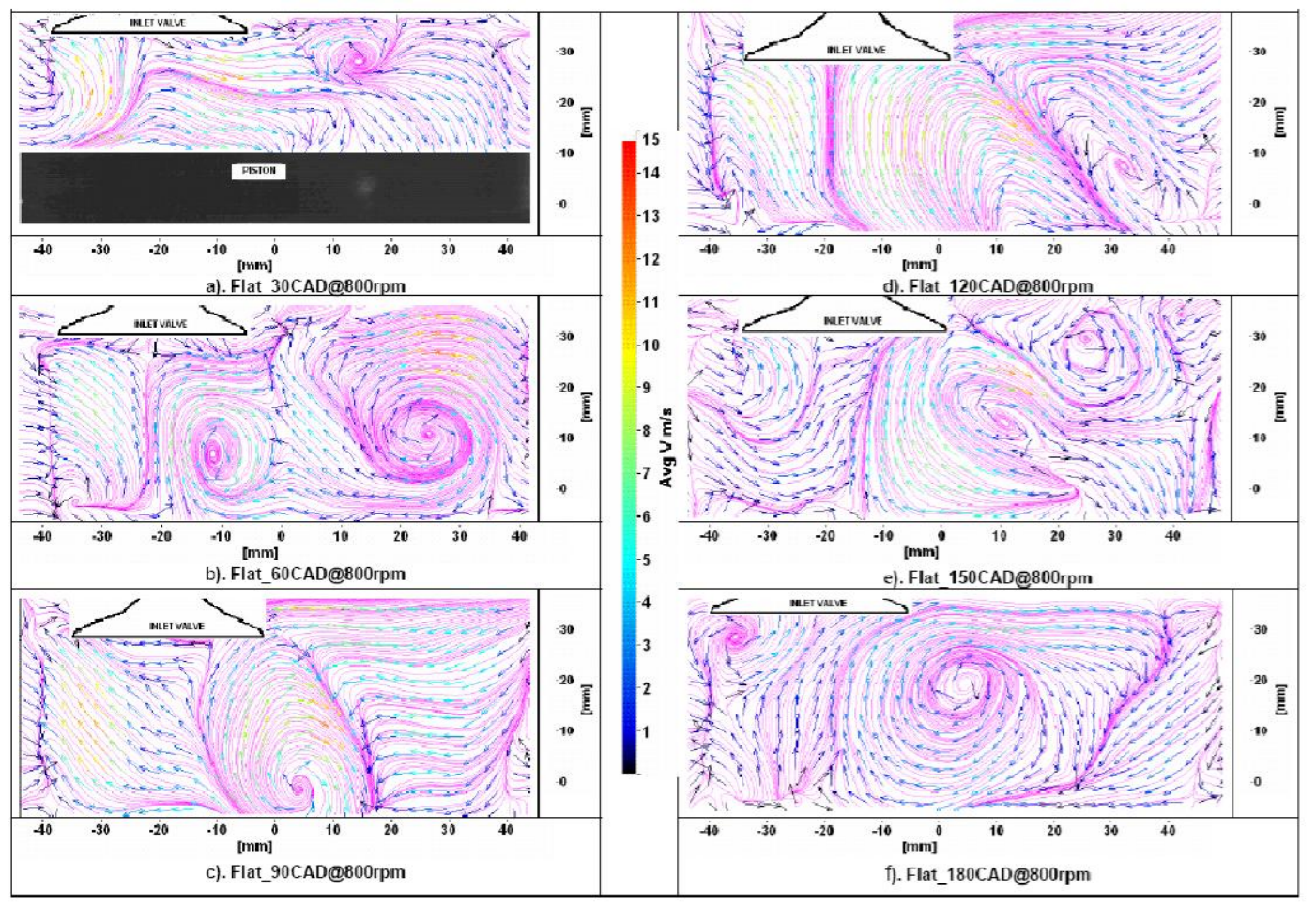

Fig. 6. The ensemble average velocity vectors during intake at an engine speed of $800 \mathrm{rev} / \mathrm{min}$.

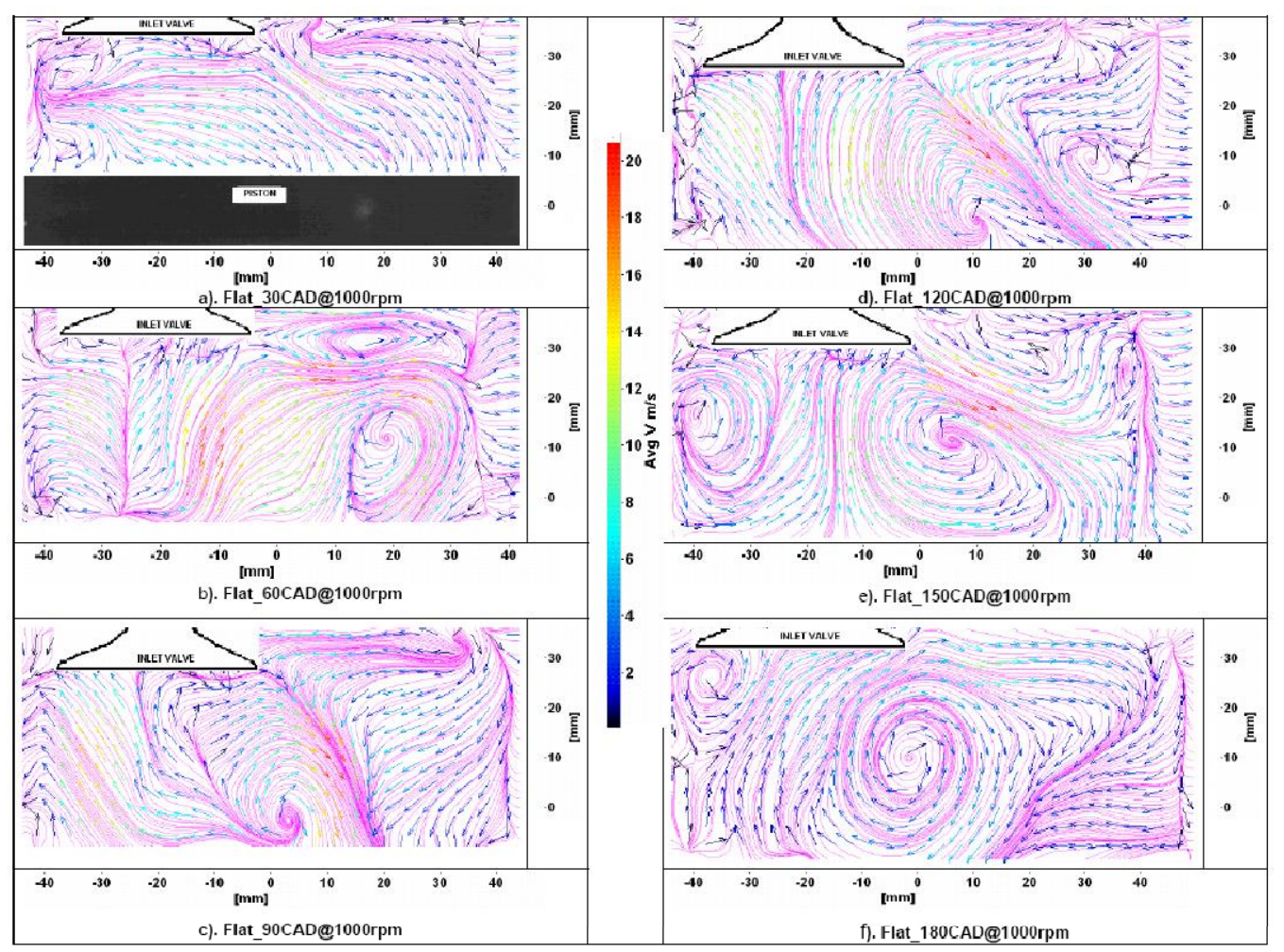

Fig. 7. The ensemble average velocity vectors during intake at an engine speed of $1000 \mathrm{rev} / \mathrm{min}$. 


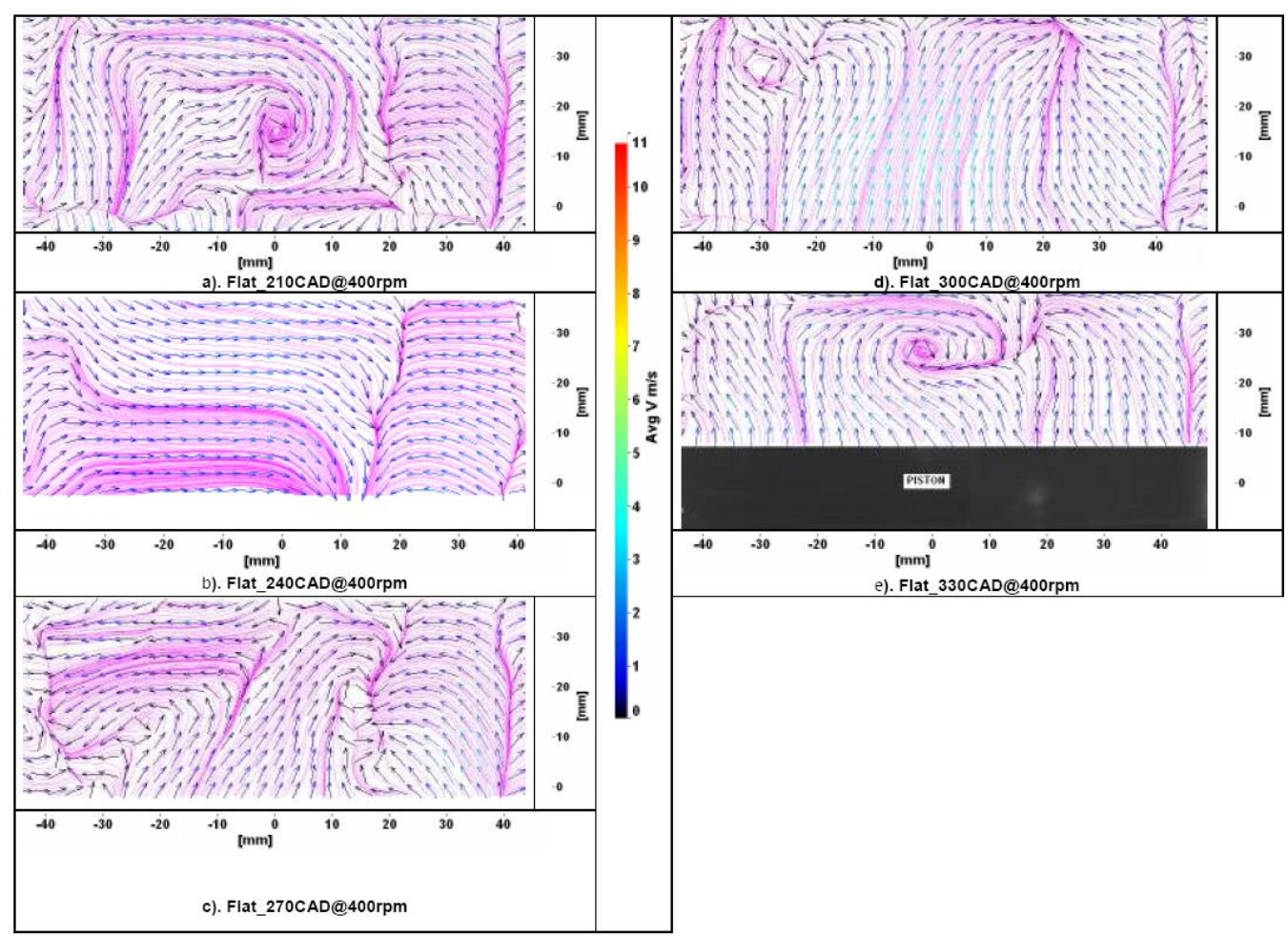

Fig. 8. The ensemble average velocity vectors during compression stroke at an engine speed of $400 \mathrm{rev} / \mathrm{min}$.

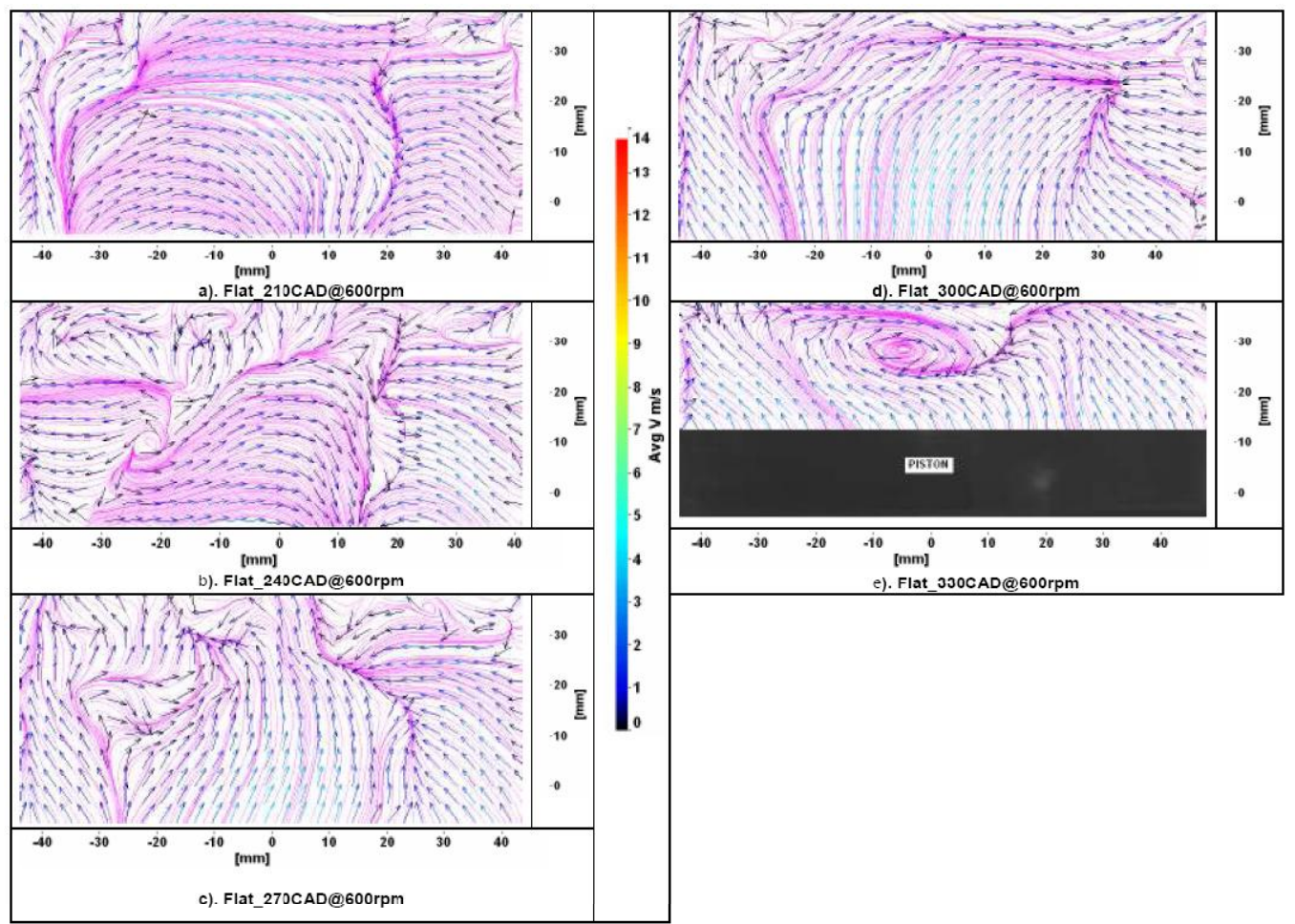

Fig. 9. The ensemble average velocity vectors during compression stroke at an engine speed of $600 \mathrm{rev} / \mathrm{min}$., 


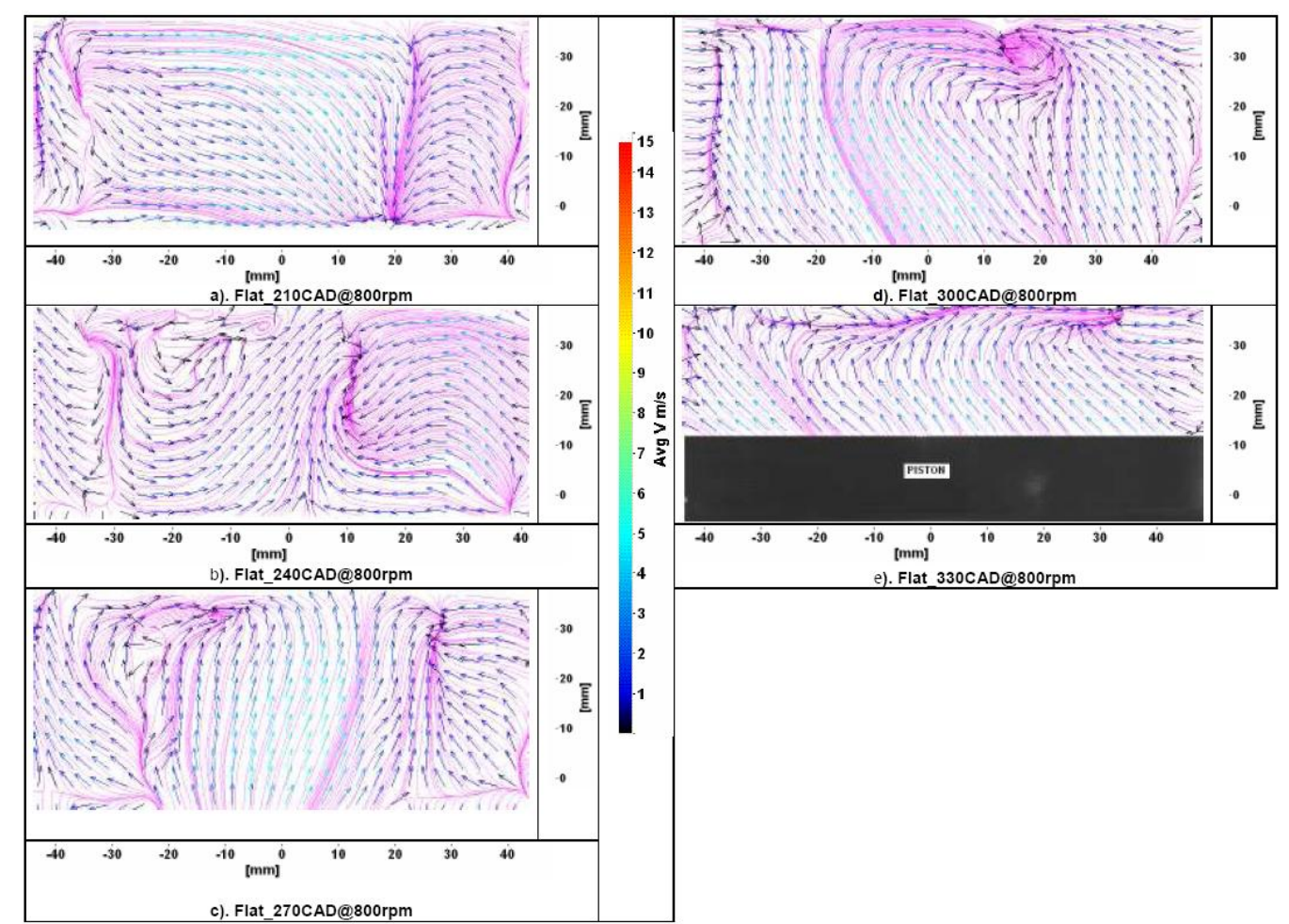

Fig. 10. The ensemble average velocity vectors during compression stroke at an engine speed of $800 \mathrm{rev} / \mathrm{min}$.

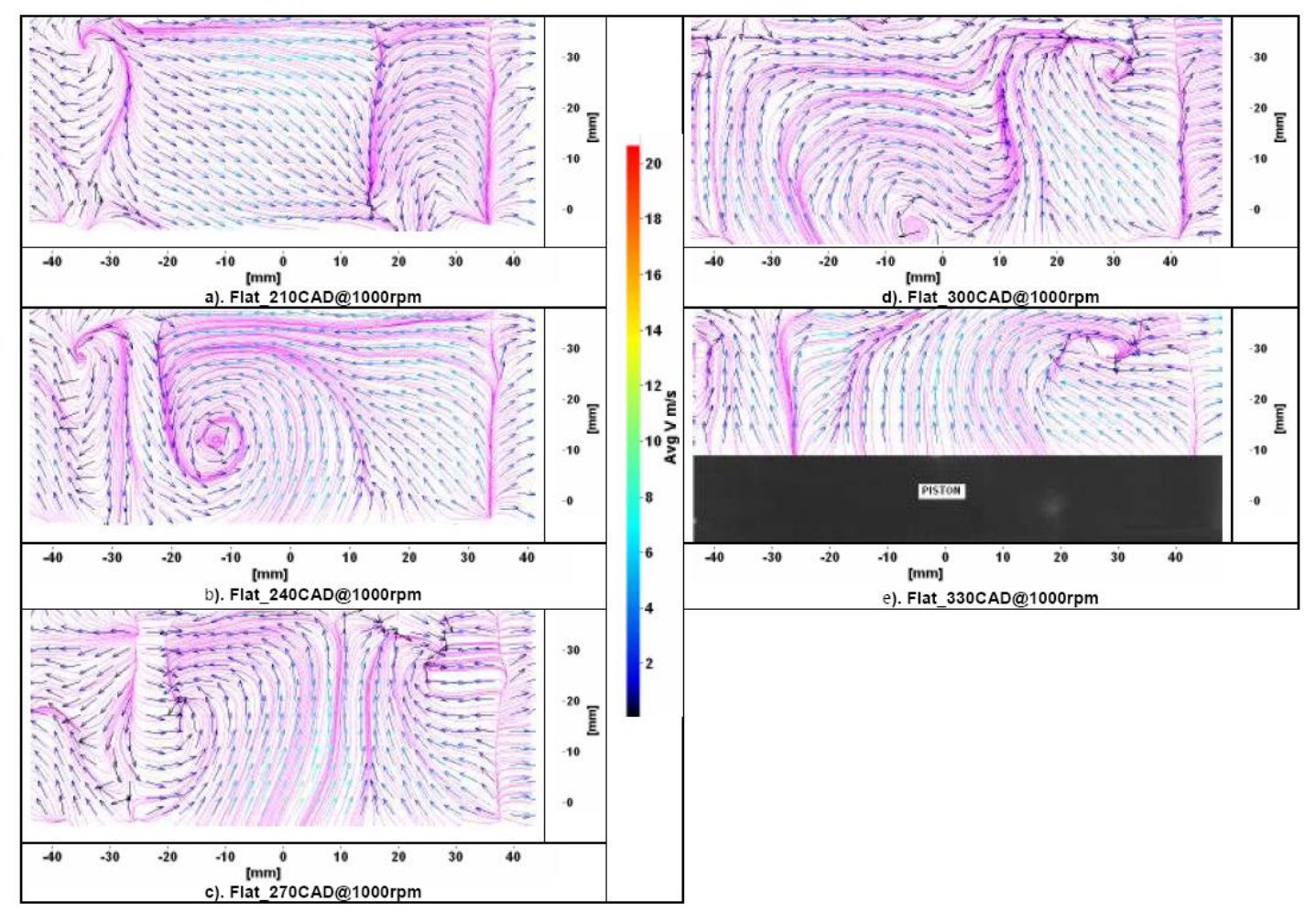

Fig. 11. Ensemble average velocity fields during compression stroke at an engine speed of $1000 \mathrm{rev} / \mathrm{min}$. 


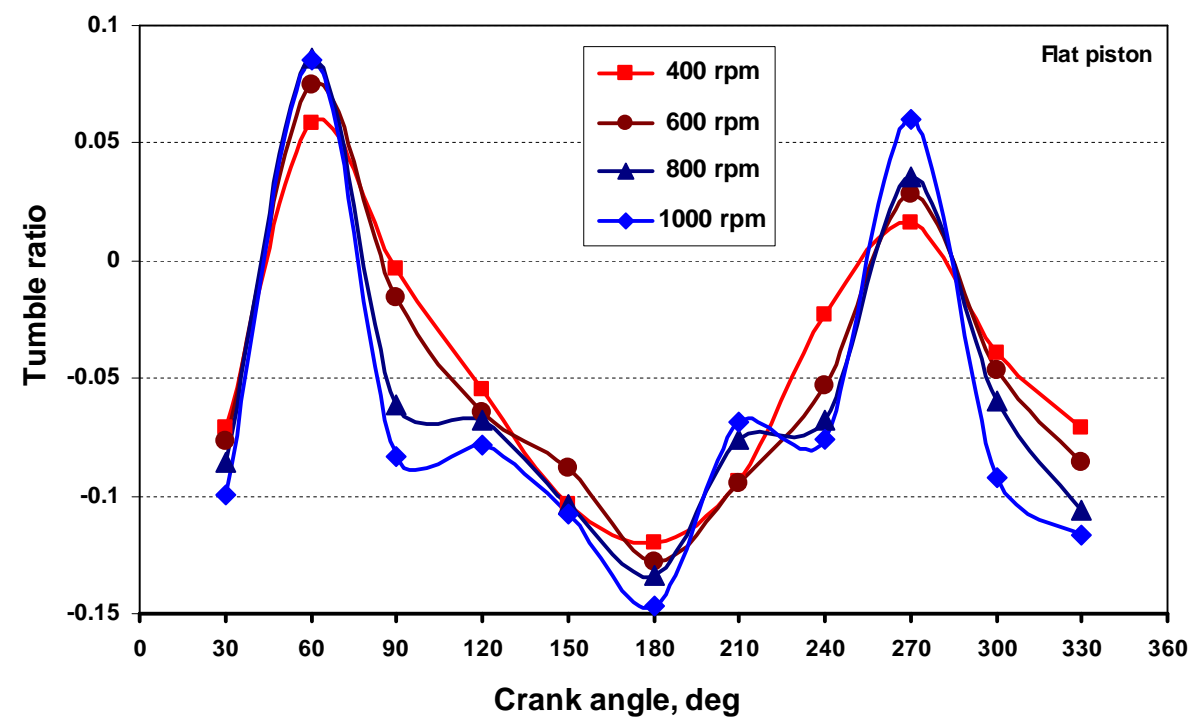

Fig. 12. Variation of tumble ratio with crank angle positions at various engine speeds

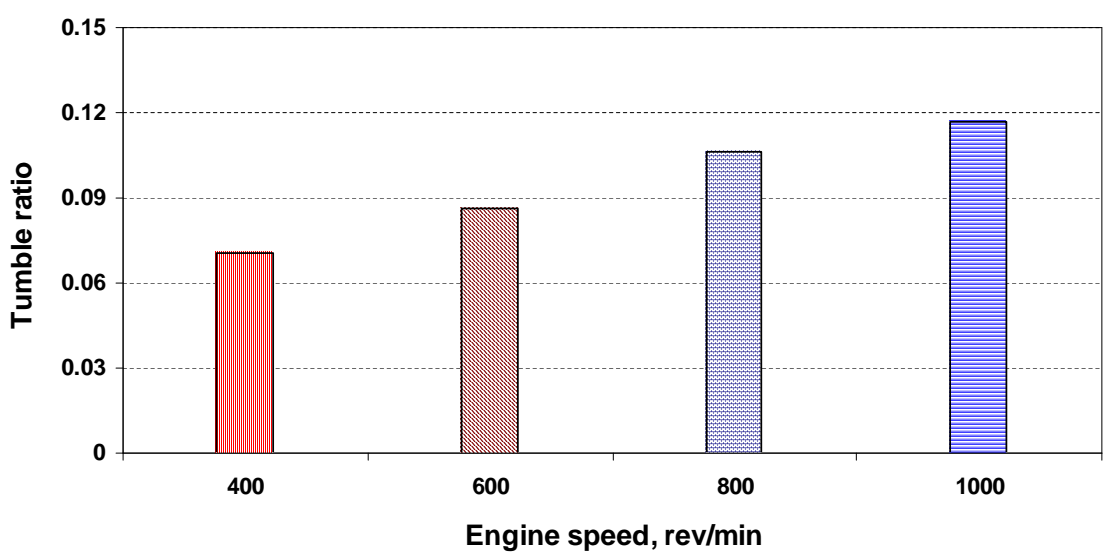

Fig. 13. Variation of tumble ratio at $330 \mathrm{CAD}$ for various engine speeds

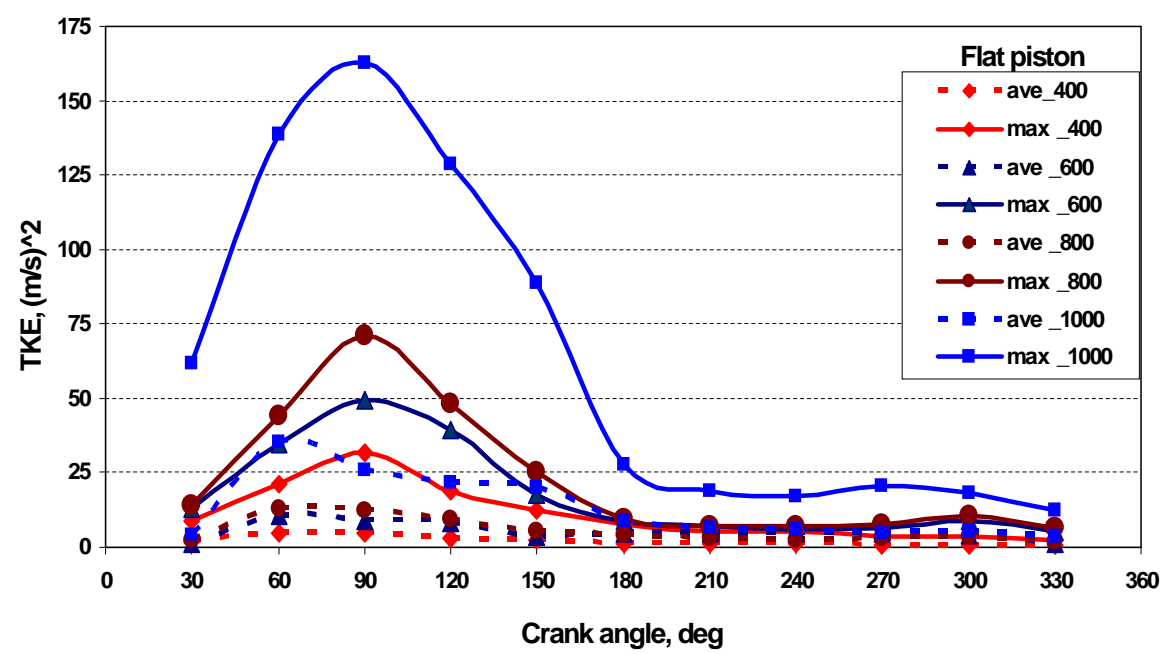

Fig. 14. Variation of average and maximum turbulent kinetic energy with crank angle positions at various engine speeds 
B. Murali Krishna and J.M. Mallikarjuna / JAFM, Vol. 4, No. 1, pp. 1-14, 2011.

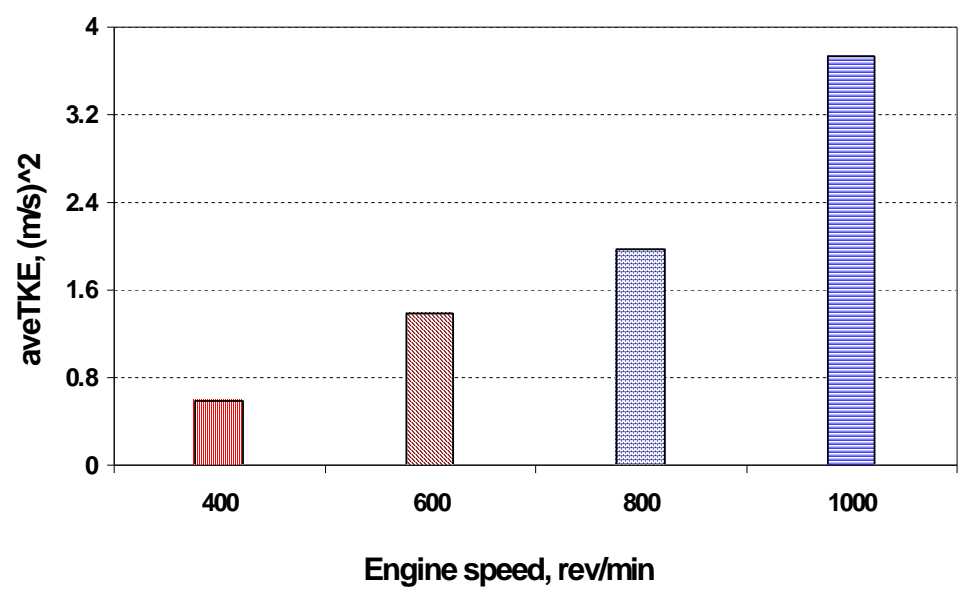

Fig. 15. Variation of average turbulent kinetic energy at $330 \mathrm{CAD}$ at various engine speeds

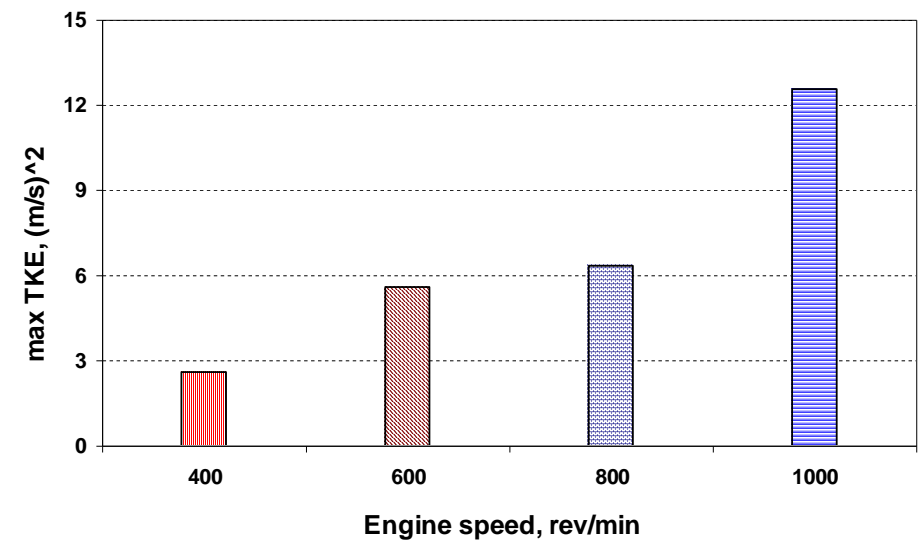

Fig. 16. Variation of maximum turbulent kinetic energy at $330 \mathrm{CAD}$ at various engine speeds 